\title{
A Busca de um Currículo Interdisciplinar e Contextualizado para Ensino Técnico Integrado ao Médio*
}

\section{The Search for an Interdisciplinary and Contextualized Curriculum from Integrated Technical Education to Middle School}

\author{
Fernanda Pereira Santos ${ }^{* *}$ \\ Célia Maria Fernandes Nunes ${ }^{* * *}$ \\ Marger da Conceição Ventura Viana ${ }^{* * * *}$
}

\begin{abstract}
Resumo
A análise da integração da disciplina Matemática juntamente às demais ofertadas no Ensino Médio Integrado a Educação Profissional Técnica consiste no objetivo deste artigo, que apresenta os resultados de uma pesquisa empírica fundamentada em reflexões de autores que discutem o ensino de Matemática e a educação profissional de nível médio. O estudo apontou que existe relação entre as disciplinas técnicas e a Matemática, visto que as primeiras, em alguns casos, necessitam dos conhecimentos da segunda para que seus assuntos sejam apreendidos pelos estudantes. Concluiu-se que é possível elencar os assuntos de Matemática que podem ser ministrados no Ensino Médio Integrado de forma contextualizada e interdisciplinar, a fim de atender a demanda das disciplinas técnicas, da Matemática e o objetivo formativo profissional do educando.
\end{abstract}

Palavras-chave: Contextualização. Interdisciplinaridade. Ensino Integrado. Instituto Federal de Educação. Currículo.

\begin{abstract}
The analysis of the mathematics discipline integration along with other disciplines offered in the Integrated High School Technical Professional Education is the purpose of this paper, which presents the results of an empirical research based on reflections of authors who discuss mathematics teaching and the secondary level of professional

\footnotetext{
* Uma primeira versão deste artigo foi publicada no Chile, em dezembro de 2015, no livro Desafíos y Tensiones en la Gestión del Currículo: Teoría y Prática, pela Universidade Católica Silva Henríquez.

** Mestre em Educação Matemática pela Universidade Federal de Ouro Preto (UFOP). Professora do Instituto Federal de Educação, Ciência e Tecnologia Baiano, Guanambi, Bahia, Brasil. Endereço para correspondência: Rua João José Rescala, 62A, Apto 804, Imbuí, CEP 41720-130, Salvador, Bahia, Brasil. E-mail: fernandasantos.fps@gmail.com.

**** Doutora em Educação pela Pontifícia Universidade Católica do Rio de Janeiro (PUC-Rio). Professora Associada da Universidade Federal de Ouro Preto (UFOP), Mariana, Minas Gerais, Brasil. Endereço para correspondência: Universidade Federal de Ouro Preto, Instituto de Ciências Humanas e Sociais, Rua do Seminário, s/n, Centro, CEP 35420-000, Mariana, Minais Gerais, Brasil.E-mail: cmfnunes@gmail.com.

***** Doutora em Ciências Pedagógicas pelo Instituto Central de Ciências Pedagógicas (ICCP), Cuba. Professora Associada da Universidade Federal de Ouro Preto (UFOP), Ouro Preto, Minas Gerais, Brasil. Endereço para correspondência: Universidade Federal de Ouro Preto, Centro de Educação Aberta e a Distância-CEAD, Campus Universitário Morro do Cruzeiro, Bauxita, CEP 35400000, Ouro Preto, Minas Gerais, Brasil. E-mail: margerv@ terra.com.br.
} 
education. The survey showed that there is a relationship between technical subjects and mathematics, since the first, in some cases, require the knowledge of the second so that its content is understood by students. We concluded that it is possible to list the Mathematics subjects that can be taught in the Integrated School in a context and interdisciplinary manner in order to meet the demand of technical disciplines, of mathematics and the professional educational purpose of the course.

Keywords: Contextualization. Interdisciplinary. Integrated education. Federal Institute of Education. Curriculum.

\section{Introdução}

O modelo de Educação Básica de Nível Médio normatizado pela legislação federal brasileira até o ano de 2004 era dualista: ofertava um ensino propedêutico, destinado a preparar o educando apenas para acesso ao Nível Superior de Ensino; ou se destinava a uma formação de caráter técnico-profissional, aliando à Educação Básica o ideário da preparação para atender ao mercado de trabalho. Após esse período surgiu no país uma nova forma de oferta de cursos de Nível Médio, denominada Educação Profissional Técnica de Nível Médio Integrada ao Ensino Médio ou Ensino Médio Integrado, "oferecida somente a quem já tenha concluído o Ensino Fundamental, sendo o curso planejado de modo a conduzir o aluno à habilitação profissional técnica de nível médio, na mesma instituição de ensino, contando com a matrícula única para cada aluno" (BRASIL, 2004, art. 4º́ É uma modalidade de ensino que possibilita aos alunos cursarem disciplinas da base nacional comum em conjunto com outras que são específicas da formação profissional, tais como Topografia, Desenho Técnico, Gestão do Agronegócio e Mecânica, chamadas disciplinas técnicas. Esses cursos devem atender à demanda de oferecer uma formação básica e técnica simultaneamente, buscando acabar com o "conflito existente em torno do papel da escola, de formar para a cidadania ou para o trabalho produtivo [...]" (RAMOS, 2005, p. 106).

Com isso, para a efetivação da proposta dos cursos integrados, é necessário construir um currículo que possibilite uma aprendizagem uniforme em cursos cuja formação básica do Ensino Médio deve estar associada à formação técnica, pois nesse modelo formativo não é aceitável uma educação unitária que se articule em prol exclusivo do trabalho ou da formação para o nível de ensino seguinte. É importante deixar claro que "trata-se de um único curso, com projeto pedagógico único, com proposta curricular única, [...] todos os seus componentes curriculares devem receber tratamento integrado, nos termos do projeto pedagógico da instituição de ensino" (BRASIL, 2004, p.08). 
Na Rede Federal de Ensino, a oferta de cursos integrados para a formação técnica ocorre, prioritariamente, em Institutos Federais de Educação, Ciência e Tecnologia (IFET). São instituições de ensino que têm a finalidade de "desenvolver a educação profissional e tecnológica como processo educativo e investigativo de geração e adaptação de soluções técnicas e tecnológicas às demandas sociais e peculiaridades regionais" (BRASIL, 2008). Os IFET devem ofertar no mínimo 50\% (cinquenta por cento) de suas vagas para cursos da modalidade integrada, sempre com o objetivo de estimular e apoiar processos educativos que levem à geração de trabalho e renda e à emancipação do cidadão na perspectiva do desenvolvimento socioeconômico local e regional (BRASIL, 2008).

A ideia do Ensino Integrado, de associar a formação básica com a técnica, não significa abandonar os conteúdos mínimos da base nacional comum. O objetivo é direcioná-los de forma a valorizar interesses das Instituições de Ensino que ofertam essa modalidade e da comunidade em que estão inseridas. Isso possibilita que os estudantes relacionem os conteúdos nas disciplinas propedêuticas à futura profissão técnica que poderão exercer, já que as questões específicas da área técnica necessitam dos conhecimentos gerais dessas e, assim, é preciso apreendê-los para diversos fins além daqueles que motivam sua apreensão (BRASIL, 2007).

Ao refletir sobre a formação integrada, Ciavatta (2005) conclui que esta implica em tratar a educação como uma totalidade social, ou seja, a educação geral deve se tornar parte inseparável da educação profissional, existindo a necessidade de enfocar o trabalho como princípio educativo, de forma a superar a dicotomia trabalho manual/trabalho intelectual, objetivando a formação de trabalhadores capazes de atuar como dirigentes e cidadãos. Um projeto de ensino médio integrado ao ensino técnico, que possui como eixos a ciência, a cultura e o trabalho, deve superar o conflito histórico "existente em torno do papel da escola, de formar para a cidadania ou para o trabalho produtivo e, assim, o dilema de um currículo voltado para as humanidades ou para as ciências e tecnologia" (FRIGOTTO, RAMOS E CIAVATTA, 2005, p. 17).

As especificidades do ensino integrado, tendo como referência documentos oficiais que subsidiam essa modalidade de ensino, enfatizam a necessidade da utilização da interdisciplinaridade e da contextualização para guiar esse modelo educativo. Quando se agrega, a esse fator, a escassez de trabalhos que associem a Educação Profissional e a Educação Matemática (GONÇALVES e PIRES, 2014) tem-se a justificativa de quão importante são estudos que versem sobre essa temática. Assim, este artigo apresenta os dados de uma pesquisa 
que teve como objetivo identificar os conteúdos curriculares de Matemática que podem auxiliar professores dessa disciplina a desenvolver um ensino interdisciplinar e contextualizado, com os estudantes do Curso Técnico Integrado ao Ensino Médio, possibilitando agregar ao ensino da Matemática características técnico-profissionais, sem deixar de considerar as especificidades fundamentais dessa disciplina.

\section{A contextualização e a interdisciplinaridade na Educação Profissional Integrada}

No currículo dos cursos Técnicos Integrados ao Médio, conhecidos pelas autoras, as disciplinas básicas não estão associadas às técnicas, ou vice versa, mostrando a necessidade de formatação dos currículos existentes. O Documento Base da Educação Profissional Técnica de Nível Médio Integrada ao Ensino Médio (BRASIL, 2007) define currículo como sendo "uma seleção de conhecimentos a serem ensinados e aprendidos dependendo da finalidade e dos objetivos educacionais" (p.49).

Saviani (1998) define currículo a partir dos aspectos culturais, afirmando que nele estão inclusas as matérias de ensino, suas distribuições pelos níveis escolares e sua carga horária, sendo o "produto de uma seleção realizada no seio da cultura" (SAVIANI, 1998, p.35). Segundo a autora

O currículo diz respeito à seleção, seqüência e dosagem de conteúdos da cultura a serem desenvolvidos em situações de ensino-aprendizagem. Compreende conhecimentos, idéias, hábitos, valores, convicções, técnicas, recursos, artefatos, procedimentos, símbolos etc... dispostos em conjuntos de matérias/disciplinas escolares e respectivos programas, com indicações de atividades/experiências para sua consolidação e avaliação (SAVIANI, 2003, p. 35).

Coll (2006) afirma que, para definir o que se entende por currículo, é preciso verificar as funções que este deve desempenhar, ou seja, as atividades que correspondem a uma finalidade e que são executadas de acordo com um plano de ação determinado. $\mathrm{O}$ autor define currículo "como o projeto que preside as atividades educativas escolares, define suas intenções e proporciona guias de ação adequadas e úteis para os professores, que são diretamente responsáveis pela sua execução" (COLL, 2006, p. 45).

Considerando que o currículo é parte indissociável da educação escolar, é possível notar aspectos semelhantes nas definições de Saviani e Coll, visto que ambos consideram que a 
educação deve assegurar que os membros de um grupo "adquiram a experiência social historicamente acumulada e culturalmente organizada" (COLL, 2006, p. 42).

Grundy (1987, apud SACRISTÁN, 2000) que, apesar de negar a possibilidade de conceituar currículo, compreende-o com uma construção cultural, não o concebe como um objeto prescrito:

O currículo não é um conceito, mas uma construção cultural. Isto é, não se trata de um conceito abstrato que tenha algum tipo de existência fora e previamente à experiência humana. É, antes, um modo de organizar uma série de práticas educativas (GRUNDY 1987 apud SACRISTÁN, 2000, p. 14).

As práticas educativas mencionadas pelo autor incluem interesses e características da sociedade em que a escola está inserida, seleção e organização de conteúdos e metodologias utilizadas no processo de ensino e de aprendizagem. O autor complementa sua compreensão de currículo afirmando que:

Numa primeira aproximação e concretização do significado amplo que nos sugere, propomos definir o currículo como o projeto seletivo de cultura, cultural, social, política e administrativamente condicionado, que preenche a atividade escolar e que se torna realidade dentro das condições da escola tal como se acha configurada (GRUNDY, 1987 apud SACRISTÁN, 2000, p. 34).

Para adotar uma definição para esse estudo, não se pode desconsiderar que o Brasil é um país de proporções continentais e que não existe uma cultura única, as culturas das comunidades são variadas. Aparentemente não seria possível a existência de um único currículo que perpassasse toda essa multiplicidade cultural, seria necessário a orientação de percepção da escola como uma cultura própria e única, em que se deve buscar seus interesses a fim de selecionar o que lhe cabe ou não usar. O projeto seletivo de cultura proposto por Grundy (1987 apud SACRISTÁN, 2000) se refere a isso, o que torna realidade dentro das condições da escola tal como se acha configurada neste país.

Viana (2002), baseando-se em diversos pesquisadores do currículo e numa ampla pesquisa teórica e empírica, construiu sua definição de currículo, apropriada tanto para elaborar como para aperfeiçoar um currículo voltado à formação profissional. Em sua análise, o currículo pode ser definido como um sistema de componentes que orientam a formação profissional relacionando teoria, prática e pesquisa. Após argumentações, a autora enumera os componentes essenciais de um currículo.

No caso da formação profissional, o sistema é composto pelo perfil do profissional, por objetivos, áreas de estudo, disciplinas, concepção de prática pedagógica, investigação, 
componente acadêmico, relação entre teoria/prática/pesquisa, processo de ensino aprendizagem e sistema de avaliação (VIANA, 2002, p. 10). ${ }^{1}$

Ademais, Viana (2002) aponta como elaborar tais componentes, envolvendo toda a comunidade interessada no currículo, fazendo com que este fique impregnado da cultura de seus construtores e seus componentes inter-relacionados, pois formam um sistema e possibilitam a interdisciplinaridade e estão contextualizados, já que a construção tem início com a definição do profissional a ser formado.

Relacionando as concepções de currículo apresentadas com a educação profissional na modalidade integrada, este estudo utilizou uma definição que contemplasse os autores mencionados, formalizando o currículo como um projeto seletivo de cultura que faz parte de toda a atividade escolar e que se materializa no cotidiano da escola, relacionando teoria e prática, considerando o perfil do profissional que se deseja formar e os objetivos do curso e das disciplinas que são ministradas, levando em consideração os conteúdos, recursos e procedimentos que serão utilizados.

Sabendo que "o currículo integrado organiza o conhecimento e desenvolve o processo de ensino-aprendizagem de forma que os conceitos sejam apreendidos como sistema de relações de uma totalidade concreta que se pretende explicar/compreender" (BRASIL, 2007, p. 42), percebese que a utilização da interdisciplinaridade e da contextualização, na apreensão e compreensão dos conteúdos, responde às necessidades específicas de uma formação com duplo objetivo formativo e que seja capaz de oportunizar sentido aos múltiplos significados que serão construídos pelos estudantes ao longo de seu desenvolvimento acadêmico-profissional. No entanto, apesar dessa associação estar prevista na legislação vigente, como já foi mencionado, inexistem parâmetros que determinam os temas/conteúdos que devem ser estudados através da interdisciplinaridade e da contextualização para a efetivação de uma formação satisfatória.

Considerando a premissa de que o apoio das disciplinas propedêuticas possibilita a compreensão dos conteúdos das disciplinas técnicas, nesta pesquisa observou-se a necessidade da Matemática auxiliar no desenvolvimento de capacidades relacionadas à compreensão e aplicação dos conteúdos técnicos que devem ser desenvolvidos pelos estudantes durante o curso integrado. O Parecer $n^{\circ}$ 15/98, do Conselho Nacional de Educação (BRASIL, 1998), tece considerações sobre a interdisciplinaridade no Ensino Médio ao afirmar que é um recurso que amplia as

\footnotetext{
${ }^{1}$ Tradução nossa.
} 
possibilidades de interação não apenas entre as disciplinas nucleadas em uma área, mas também entre as próprias áreas de nucleação. Conforme observado durante o desenvolvimento dessa pesquisa, "em diferentes documentos oficiais, identificamos a proposta de tomar a interdisciplinaridade como um eixo norteador da Educação Profissional" (GONÇALVES e PIRES, 2014, p.235), sendo que no Ensino Técnico Integrado essa proposta pode ser efetivada durante todos os anos letivos, sempre com o estreitamento de laços com disciplinas que farão parte da formação profissional do estudante.

A interdisciplinaridade deve considerar o contexto educacional ou objetivo formativo em que será desenvolvida. Considerando que

Cada disciplina precisa ser analisada não apenas no lugar que ocupa ou ocuparia na grade, mas nos saberes que contemplam, nos conceitos enunciados e no movimento que esses saberes engendram, próprios de seu lócus de cientificidade. Essa cientificidade, então originada das disciplinas, ganha status de interdisciplina no momento em que obriga o professor a rever suas práticas e a redescobrir seus talentos, no momento em que ao movimento da disciplina seu próprio movimento for incorporado. $\mathrm{O}$ conceito de interdisciplinaridade [...] encontra-se diretamente ligado ao conceito de disciplina, onde a interpenetração ocorre sem a destruição básica às ciências conferidas (FAZENDA, 2008, p. 18-19).

A adoção da interdisciplinaridade não dilui e nem elimina as disciplinas, e sim mantém sua individualidade, integrando-as para a construção de novos conhecimentos e favorecendo o uso de novas formas de aproximação com a realidade social e laboral. O que se deseja é agregar à organização curricular a possibilidade de "analisar a interdependência entre as disciplinas, as formas como elas se articulam, que tipos de hierarquias se estabelecem, que influências essas hierarquização desempenha nos currículos” (PIRES, 2004, p. 34).

Observa-se a necessidade de eliminar as fronteiras curriculares existentes em prol de um processo de ensino que permita aos alunos perceberem que um único conteúdo pode ser essencial para o aprendizado de diversas disciplinas, nos mais variados momentos da formação profissional. A realização de ações interdisciplinares, seguindo a conceituação de Fazenda (2008), vai ao encontro dos objetivos formativos dos cursos integrados, sendo necessária para a efetivação de uma educação profissional de qualidade.

No que se refere à contextualização, Lopes (2002) afirma que esta, "associada à interdisplinaridade, vem sendo divulgada pelo MEC como princípio curricular central” (p.390). Como já mencionado nesse artigo, este é um dos fundamentas de como deve ser ofertado o Ensino Integrado em Institutos Federais de Educação, sem inviabilizar a aprendizagem da Matemática por ela mesma, de forma a não perder o objetivo formativo específico da disciplina. 
Lopes (2002) também afirma que "contextualização é um dos processos de formação das competências necessárias ao trabalho na sociedade globalizada e à inserção no mundo tecnológico" (p.395), sendo que este enfoque difere do conceito de cotidiano e de valorização dos saberes populares.

D’Ambrosio (2001) reforça a importância da contextualização ao apresentar questionamentos que motivam possibilidades de um ensino contextualizado dentro de um contexto sócio histórico:

A contextualização é essencial para qualquer programa de educação de populações nativas e marginais, mas não menos necessária para as populações dos setores dominantes se quisermos atingir uma sociedade com equidade e justiça social. [...] Afinal, como deixar de relacionar os Elementos de Euclides com o panorama cultural da Grécia Antiga? Ou a adoção da numeração indo-arábica na Europa como florescimento do mercantilismo nos séculos XIV e XV? E não se pode entender Newton descontextualizando (D'AMBRÓSIO, 2001, p. 114-115).

Associando a formação proposta pelo Ensino Médio Integrado percebe-se que a contextualização se faz necessária nessa modalidade de ensino, já que podem existir lacunas entre os conteúdos lecionados e o aprendizado profissional dos alunos, dificultando a identificação destes com os objetivos propostos pelo curso. É preciso considerar, sempre que possível, a possibilidade de construção de significados a partir de questões internas da própria Matemática, evitando assim o descarte ou desinteresse por conteúdos por não terem aplicabilidade concreta e imediata com os interesses laborais dos estudantes. Ao relacionar o Ensino Integrado com a contextualização percebe-se que a inter-relação entre as disciplinas pode permitir abordagens que considerem o contexto futuro no qual o aluno poderá trabalhar (SANTOS, 2012).

\section{Os procedimentos da investigação}

O estudo foi desenvolvido no Instituto Federal de Educação, Ciência e Tecnologia Baiano, em um campus localizado na zona rural do perímetro irrigado do Distrito de Ceraíma, dentro do município de Guanambi, no estado da Bahia, antes uma Escola Agrotécnica Federal. Atuando há mais de quinze anos com a oferta de cursos de nível médio, este IFET atualmente oferece cursos nas mais variadas áreas: Técnico em Agricultura e Técnico em Zootecnia (para quem já possui o Ensino Médio); Técnico Integrado em Agropecuária, Técnico Integrado em Agroindústria (para quem tem o Ensino Fundamental); Técnico Integrado em Informática (para pessoas maiores de 18 anos); cursos de nível superior (Licenciatura em Química, Bacharelado em 
Agronomia, Tecnólogo em Alimentos, Tecnólogo em Análise e Desenvolvimento de Sistemas); e Mestrado Profissional em Produção Vegetal no Semiárido.

Dentre os cursos de Ensino Médio Integrado ao Técnico ofertados escolheu-se, aleatoriamente, o Técnico em Agropecuária para a realização desse estudo. Ele é constituído de regime seriado anual (três séries), cuja carga horária é dividida em duas partes, 2.240 horas para as disciplinas da área técnica e 720 horas para as disciplinas da base nacional comum, e os estudantes participam de aulas de segunda a sexta-feira (das 07h30min às $11 \mathrm{~h} 30 \mathrm{~min}$ e das 13h30min às $17 \mathrm{~h} 30 \mathrm{~min}$ ) e, esporadicamente, aos sábados. O projeto do curso analisado, que estava em vigor no período em que esta pesquisa foi realizada, foi o implementado no ano de 2005, embora o curso tenha sido instituído desde a fundação da Escola Agrotécnica que deu origem ao IFET, no ano de 1993.

Também foram estudadas normativas legais que devem direcionar as ações a serem efetivadas pelo IFET, tais como as Diretrizes Curriculares Nacionais para a Educação Profissional Técnica de Nível Médio (BRASIL, 2011) e o Documento Base da Educação Profissional Técnica de Nível Médio Integrado ao Ensino Médio (BRASIL, 2007), além das produções de diversos autores que fazem estudos na área de educação técnica profissional, tais como Frigotto, Ramos e Ciavatta (2005).

A análise dessa bibliografia teve como foco principal entender os objetivos e especificidades de um Curso Integrado para, de posse dessas informações, definir a metodologia da pesquisa, os sujeitos e os instrumentos de pesquisa que seriam utilizados. Nessa etapa, percebeu-se que os objetivos da aprendizagem propostos pelo Projeto do Curso eram distintos dos existentes nas normativas legais, já que a Matemática priorizava unicamente a formação básica para continuidade de estudos e as disciplinas técnicas buscavam formar o estudante exclusivamente para a atuação profissional técnica. Tratava-se de um ensino profissional separado do propedêutico, sem conexões entre os conteúdos curriculares, apesar de todos pertencerem a uma mesma matriz. Verificou-se que não havia integração entre as disciplinas, e sim uma separação entre o ensino básico e o técnico, fato corroborado pela divisão da carga horária entre as disciplinas e a inexistência de integração entre as mesmas no Projeto do Curso.

Os sujeitos selecionados para participar da pesquisa foram os membros da comunidade acadêmica que estavam diretamente envolvidos com a implementação/execução do Projeto do Curso de Agropecuária e que pudessem descrever as relações existentes entre as disciplinas da 
área técnica e a Matemática. Esses participantes foram organizados em dois grupos distintos para otimizar a aplicação dos instrumentos e a análise dos dados: Grupo 1 - formado pelos professores das disciplinas técnicas que estavam atuando no curso durante o segundo semestre do ano letivo de 2011; e Grupo 2 - composto pelos estudantes do Curso de Agropecuária regularmente matriculados no ano letivo de 2011.

O Grupo 1 foi selecionado aleatoriamente entre os 14 (quatorze) docentes do IFET que trabalhavam com as disciplinas técnicas, sendo que 08 (oito) eram do sexo feminino e 6 (seis) do sexo masculino. Estimou-se a participação de $60 \%$ (sessenta por cento) destes, um professor por cada disciplina técnica do Projeto do Curso, porém apenas 7 (sete) docentes da amostra pretendida aceitaram participar da pesquisa. Ao observar os currículos destes participantes, obtidos na Plataforma Lattes, pôde-se perceber que apenas um não possuía formação na área da disciplina que lecionava, mas isto não o impedia de ter conhecimento acerca dos assuntos específicos, já que ministrava aulas no curso há quase três anos e era graduado em uma área afim da Agropecuária. Por outro lado, mais de $80 \%$ (oitenta por cento) dos professores que participaram do estudo possuíam curso de pós-graduação stricto sensu na área em que lecionavam, indicador que os qualificava a falarem com propriedade das disciplinas que ministravam.

A seleção do Grupo 2 recaiu sobre os estudantes matriculados em quatro turmas do curso, duas da segunda série ( 83 alunos) e duas da terceira (52 alunos), contabilizando 135 (cento e trinta e cinco) estudantes. Consideraram-se apenas essas séries, pois seus alunos já obtiveram aprovação em alguma disciplina da área técnica, ou seja, já passaram por todos os processos avaliativos e formativos de algumas disciplinas técnicas e poderiam explanar melhor a importância das mesmas, além de relacioná-la com outras da Base Nacional Comum, neste caso, com a Matemática. A participação desses alunos se fez necessária visto que são atores da aplicação do currículo na instituição escolar, participando ativamente de sua implementação e necessitando dos conhecimentos advindos deste para a escolha do caminho profissional que irão trilhar.

A tentativa das pesquisadoras em determinar uma orientação para a seleção de conteúdos curriculares indicou a aproximação profissional delas com o local onde aconteceu a pesquisa. Isso possibilitou a adesão de elementos novos e importantes para o estudo, fazendo com que a fonte direta dos dados fosse o ambiente natural, impossibilitando que as investigadoras 
separassem a ação do contexto em que a pesquisa ocorreu. Isso se enquadrou em uma característica da investigação qualitativa na qual "os investigadores introduzem-se e despendem grandes quantidades de tempo em escolas, famílias, bairros e outros locais tentando elucidar questões educativas" (BOGDAN \& BIKLEN, 1994, p.47). Devido a isso, para a efetivação do estudo, foram selecionados instrumentos condizentes com a metodologia qualitativa e com os sujeitos da pesquisa.

Os instrumentos usados para a coleta de dados com os professores foram entrevistas, questionários e o material didático utilizado por eles nas disciplinas técnicas, o que incluía artigos científicos, livros didáticos e materiais preparados pelos mesmos. A elaboração dos questionários levou em consideração informações acadêmicas e experiências profissionais relacionadas ao ensino integrado.

A partir do objetivo da pesquisa, escolheu-se utilizar entrevista semiestruturada, já que esta permite maior liberdade de comunicação e interação entre os locutores, assim os docentes poderiam falar livremente sobre episódios que ocorreram na sala de aula, detalhar sobre o material didático utilizado, sobre a postura dos alunos frente às dificuldades com o conteúdo e quaisquer outras informações que julgassem necessárias. O objetivo das entrevistas com os

professores foi descobrir se existia a necessidade de os alunos conhecerem assuntos de Matemática para a efetivação do processo de ensino-aprendizagem dos conteúdos específicos das disciplinas técnicas.

Com os estudantes foram aplicados somente questionários contendo perguntas subjetivas. Esse instrumento foi selecionado para deixar os discentes mais a vontade em externar suas opiniões e conhecimentos, fazendo com que os mesmos se sentissem seguros ao saber que não seriam identificados e pudessem escrever o que achassem pertinente. Esses questionários eram formados de perguntas referentes a cada uma das disciplinas técnicas que eles já haviam cursado, na tentativa de associá-los a conteúdos de Matemática que consideravam necessários para apreendê-las.

\section{Análise dos dados coletados e resultados obtidos}

A análise dos dados foi realizada em diferentes etapas, inicialmente estudaram-se as ementas das disciplinas técnicas (disponíveis no Projeto do Curso), em seguida verificou-se a fala 
dos docentes (após a transcrição das entrevistas) e o que responderam nos questionários. $\mathrm{Na}$ terceira etapa foram apuradas as respostas dadas pelos estudantes, seguidas pela análise dos planos de curso disponibilizados pelos professores participantes e, por fim, o estudo considerou o material didático que eles utilizavam para ministrar as aulas.

Durante a análise do Projeto do Curso, percebeu-se que diversas disciplinas da área técnica necessitavam da Matemática para serem compreendidas, entretanto muitos dos assuntos estavam relacionados a conteúdos que são lecionados no Ensino Fundamental, tais como Regra de Três, Equação do Primeiro Grau e Operações com Frações. Como esse estudo se refere ao Ensino Médio, nessa análise considerou-se apenas a menção direta a conteúdos matemáticos relacionados a essa etapa da formação discente, tendo como base a ementa da disciplina Matemática constante no Projeto do Curso. Com isso foram encontradas referências a conteúdos de Matemática relativos ao Ensino Médio nas disciplinas de Agricultura II, Irrigação e Drenagem, Agricultura III e Topografia.

Em seguida, considerando-se as entrevistas e questionários respondidos pelos professores e estudantes, foi possível obter dados mais específicos sobre a necessidade de conteúdos matemáticos para a compreensão de assuntos da área técnica. Para analisar as entrevistas e os questionários construíram-se categorias (assuntos de Matemática mencionados) como referencial inicial de análise. Segundo Minayo (1996), “as categorias são empregadas para se estabelecerem classificações. Nesse sentido, trabalhar com elas significa agrupar elementos, ideias ou expressões em torno de um conceito capaz de abranger tudo isso" (p.70). Os participantes da pesquisa confirmaram que algumas das disciplinas técnicas necessitavam de conteúdos matemáticos ministrados no Ensino Fundamental e no Médio e listaram quais seriam. Os conteúdos de Matemática lecionados no Ensino Médio que se mostraram necessários para a compreensão e entendimento dos conteúdos das disciplinas técnicas ministrados no IFET durante as três séries, considerando as falas dos participantes (estudantes e professores) e o Projeto do Curso, foram:

1. Conversão de medidas (área, volume);

2. Leitura de tabelas e gráficos;

3. Estatística;

4. Trigonometria no triângulo;

5. Funções Trigonométricas; 
6. Matemática Financeira;

7. Probabilidade;

8. Logaritmos;

9. Funções de $1^{\circ}$ e $2^{\circ}$ grau;

10. Geometria Plana;

11. Geometria Espacial.

Com base nessa lista de conteúdos foi possível verificar de que forma eles poderiam ser ministrados a fim de auxiliar na aprendizagem da disciplina de Matemática e das disciplinas técnicas, com a utilização de métodos relacionados à interdisciplinaridade e à contextualização. Esta etapa da análise suscitou a necessidade de verificar o momento em que cada conteúdo era ministrado, no decorrer do ano letivo, e para isso foram utilizados os planos de cursos elaborados pelos docentes que participaram do estudo. Junto a isso foram agregadas informações referentes aos materiais didáticos utilizados pelos professores que participaram do estudo.

Apesar do conhecimento que esses profissionais têm sobre conteúdos de Matemática, oriundos da formação que receberam, considerou-se que seria de fundamental importância a participação de um profissional licenciado em Matemática para perceber a existência de assuntos que não foram mencionados, mas que eram necessários para a apreensão dos conteúdos técnicos. Devido a isso duas das pesquisadoras analisaram todo o material didático que foi disponibilizado pelos docentes, contudo, tendo como base o objetivo da pesquisa, apenas foram considerados aqueles cujos conteúdos tinham relação com assuntos de Matemática ministrados no Curso de Agropecuária do IFET.

A análise do material didático foi realizada após dividi-los em três grupos, considerando o momento em que são lecionados no Curso de Agropecuária: Grupo 1 - referente às disciplinas lecionadas na $1^{\mathrm{a}}$ série; Grupo 2 - das disciplinas da $2^{\mathrm{a}}$ série; e Grupo 3 - disciplinas da $3^{\mathrm{a}}$ série. Nessa análise foram levadas em consideração, além da percepção das pesquisadoras sobre os materiais didáticos disponibilizados, as falas dos professores durante as entrevistas e a opinião dos estudantes constante nos questionários, bem como informações constantes no Projeto do Curso.

Analisando o plano de curso (elaborado pelo docente) da disciplina Topografia, ministrada para estudantes da segunda série, verificou-se que algumas das competências estão diretamente relacionadas com a Matemática: realizar cálculos e transformações de unidades nos 
diferentes sistemas de medidas; fazer medições lineares e angulares; realizar cálculos de ângulos e de distâncias. Toda a disciplina envolve cálculos matemáticos e o uso de raciocínio lógico para que se chegue ao objetivo principal que "é efetuar o levantamento (executar medições de ângulos, distâncias e desníveis) que permita representar uma porção da superfície terrestre em uma escala adequada" (VEIGA, ZANETTI e FAGGION, 2012 p. 1). Nessa disciplina havia a necessidade de conhecimentos relacionados a área de figuras planas, lei dos senos e cossenos, relações trigonométricas no triângulo, distância entre dois pontos, matrizes e outros assuntos, geralmente relacionados a geometria.

Quanto à disciplina Agricultura II, também ofertada no segundo ano do curso, o professor responsável disponibilizou uma quantidade grande de material (13 apostilas), dos quais apenas três continham elementos diretamente relacionados com conteúdos da Matemática do Ensino Médio lecionados no IFET pesquisado. Uma das apostilas continha slides sobre a Importância Econômica das Culturas Anuais, outra se referia às Bases Hidrológicas da Erosão e a última era um artigo sobre Identificação de Espécies para a Cobertura do Solo. Segundo o plano de curso dessa disciplina, algumas das habilidades exigidas do estudante são: conceituar e identificar a importância econômica da agricultura; reconhecer e identificar a composição volumétrica do solo; estabelecer relações entre $\mathrm{pH}$ do solo; e disponibilidade de nutrientes para as plantas e utilizar tabelas de corretivos e fertilizantes. Essas habilidades estão diretamente relacionadas à aplicação de conteúdos de Matemática, tais como análises estatísticas (gráficos e tabelas), função exponencial, construção de gráficos, logaritmos (para o cálculo do pH do solo) e polinômios (SANTOS, 2012).

Analisando o plano de curso e os outros documentos estudados, referentes à disciplina Agricultura III, ministrada na terceira série, também foi possível observar a necessidade do uso de Matemática para o seu desenvolvimento. De todo o material acessível, encontrou-se, em quatro das apostilas disponibilizadas pelo professor, elementos diretamente relacionados com conteúdos da Matemática do Ensino Médio semelhantes aos da disciplina Agricultura II e, quando realizada a associação com a fala dos docentes, dos discentes e do Projeto do Curso verificou-se a utilização de geometria plana e espacial, além de conhecimentos básicos de estatística.

Sobre a disciplina Irrigação e Drenagem, um dos docentes entrevistados afirmou que " $a$ disciplina que tem mais matemática é irrigação. Irrigação. Irrigação é pura matemática e há um 
elevado índice de reprovação. Os alunos que tem nota baixa, que estavam no conselho ${ }^{2}$, a maioria é irrigação" (D8, Entrevista, 2012). Ela é ofertada na última série do Curso de Agropecuária e necessita de conteúdos específicos de Matemática para a realização e compreensão de estruturas e modos de irrigação, apresentando envolvimentos com assuntos como função do segundo grau, logarítmica e exponencial.

Estudando o material didático desta disciplina foi possível perceber que, de fato, a Matemática é fator primordial para o sucesso/insucesso dos estudantes. Como o objetivo da irrigação é satisfazer as necessidades hídricas das culturas, adequando a quantidade de água utilizada neste processo com o tipo de solo, clima, vegetação, área plantada, velocidade do vento, entre outras coisas, são necessários cálculos que necessitam de um conhecimento aprofundado dos conteúdos mencionados, durante todo o desenvolvimento da disciplina (SANTOS, 2012).

A realização dessas etapas de análise se mostrou de fundamental importância para pesquisa, pois com os dados obtidos foi possível estabelecer se a aplicação de métodos contextualizados era possível e/ou em que momentos a interdisciplinaridade poderia se fazer presente no Curso de Agropecuária. Observou-se que nas disciplinas que são ministradas na primeira série do curso apenas há necessidade de conteúdos matemáticos do Ensino Fundamental, por isso todo o estudo foi desenvolvido considerando duas disciplinas ministradas no segundo ano do curso e mais duas no terceiro ano.

Relacionando as análises realizadas com os conteúdos didáticos lecionados em Matemática durante a efetivação do curso concluiu-se que, na segunda série do curso, durante o ensino de Geometria Plana, é possível realizar associações com a disciplina de Topografia e Agricultura II. Isso seria feito com o desenvolvimento de métodos relacionados à contextualização de conteúdos, o que envolveria a medição de terrenos não planos, no caso da disciplina Topografia, e de escolha de um esquema de plantio na disciplina Agricultura II. O esquema de plantio diz respeito à forma como as mudas são dispostas em um terreno, em esquema de quadrado, retângulo ou triângulos equiláteros (Figura 01), sendo que o último oferece mais vantagens de aproveitamento da área a ser plantada. Conhecendo esses três tipos de esquemas para alinhamento é possível estudar o aproveitamento da área e fazer alguns questionamentos aos estudantes: Qual a real vantagem do uso do esquema triângulo equilátero? Quanto de área se perde ao utilizar os outros esquemas? É possível elaborar uma função que

\footnotetext{
${ }^{2} \mathrm{O}$ docente, aqui chamado de D8, se referiu ao conselho de classe final que acontece no final do ano letivo.
} 
determine o número total de mudas em cada um dos esquemas? Como essa função seria? (SANTOS, 2012).

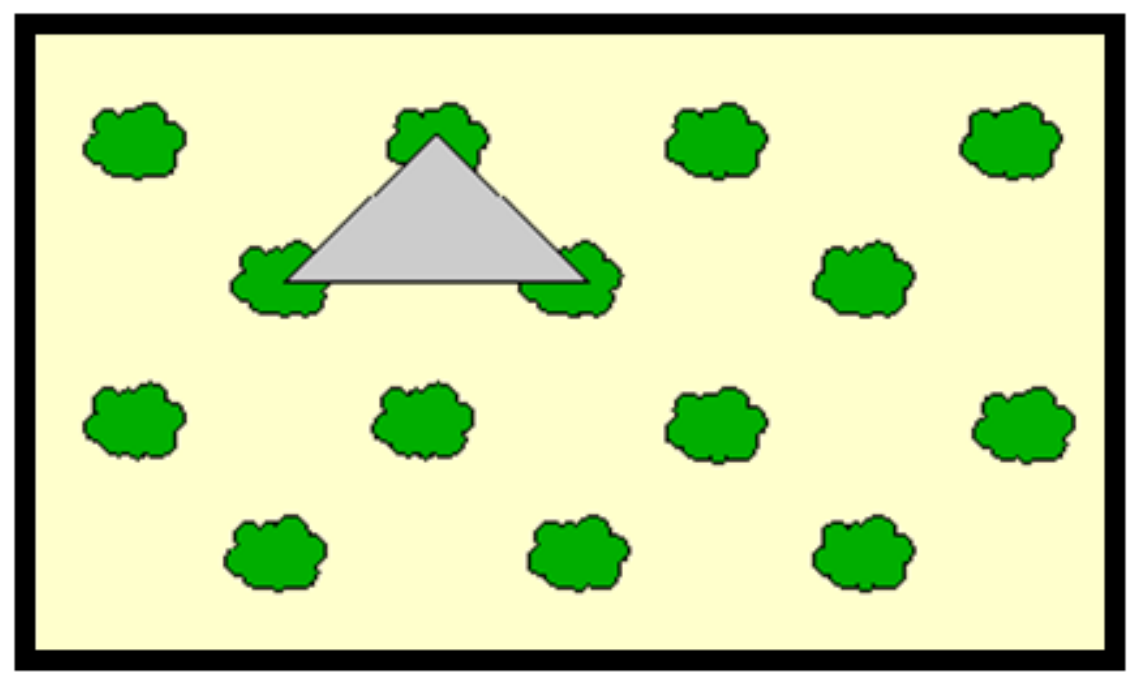

Figura 1 - Esquema de um pomar na forma triângulo equilátero. Fonte: FACHINELO, NACHTIGAL e KERSTEN, 2008.

Aos se estudar Matrizes, Geometria Espacial e Funções Trigonométricas, também durante o segundo ano do curso, a contextualização mais uma vez pode se fazer presente considerando os conteúdos dessas mesmas disciplinas, Topografia e Agricultura II, a exemplo do estudo de volumes que pode ser associado à criação de $\operatorname{covas}^{3}$ para a plantação de mudas. É muito importante que nesta fase do curso os estudantes entendam o conteúdo volume, concernente à geometria espacial, já que na abertura das covas separa-se material do solo e do subsolo para que se coloque a matéria orgânica, fertilizantes e corretivos, e em seguida efetua-se o plantio. A quantidade desses materiais deve estar associada ao volume de solo e subsolo retirados, para não exceder a capacidade da cova.

Além disso, também é possível que haja uma abordagem diferenciada dos conteúdos matrizes e trigonometria na disciplina Topografia, pois esta utiliza esses assuntos na mesma unidade letiva em que são lecionados em Matemática. O estudo do cálculo de áreas em Topografia pode ser feito usando o Método Trigonométrico, o Método de Gauss ou o Método de Sarrus, requerendo o conhecimento de matrizes e determinantes, possibilitando que os professores desenvolvam aulas conjuntamente para que a apreensão do conteúdo aconteça de forma interdisciplinar e contextualizada (SANTOS, 2012).

\footnotetext{
${ }^{3}$ São os espaços abertos na terra para que se possa efetuar o plantio cujo tamanho está relacionado com a espécie e o tipo de solo.
} 
Quanto ao assunto função exponencial, lecionado no início da segunda série do curso, há associação também em Agricultura II com o assunto de velocidade de infiltração da água em determinado solo, em que uma das fórmulas, responsável por determinar essa velocidade, é uma função exponencial que requer a compreensão de informações referentes ao estudo do sinal, a momentos de crescimento ou decrescimento e análises gráficas da função. São dois conteúdos ministrados em momentos distintos do ano letivo, mas não há impedimento do professor de Matemática tentar associar os conteúdos na tentativa de realizar uma aula contextualizada que considere conhecimentos que os estudantes irão aprofundar posteriormente.

$\mathrm{O}$ uso de funções logarítmicas e exponenciais é frequente na disciplina Irrigação e Drenagem, no cálculo da velocidade de infiltração da água no solo, por exemplo, essas equações determinam valores para que o objetivo na técnica se concretize. Como a disciplina é ministrada na terceira série do curso, e esses conteúdos matemáticos são lecionados na segunda série, a alternativa é a busca por uma contextualização que considere informações básicas sobre irrigação. O mesmo acontece quando se estuda, nessa mesma disciplina, os sistemas irrigatórios que utilizam um pivô central que se movimenta de forma circular, em que é necessário saber fazer o cálculo da área irrigada e da velocidade com que essa torre deve se movimentar através de cálculos que envolvem geometria plana (círculos) e função do segundo grau (SANTOS, 2012).

Verificou-se nos slides utilizados nas aulas da disciplina Agricultura II a existência de diversos gráficos e tabelas, com diferentes formatos e quantidades de dados publicados pelo $\mathrm{IBGE}^{4}$ que podem servir de exemplos para o estudo de conteúdos de Estatística na terceira série. Isso possibilitaria estudos contextualizados que envolvessem dados reais e que são de conhecimento e interesse dos estudantes. O mesmo conteúdo foi verificado no material didático da disciplina Irrigação e Drenagem, o que possibilitaria a realização de estudos interdisciplinares envolvendo conteúdos relacionados à Estatística (lecionados na terceira série).

Ainda referente à disciplina Irrigação e Drenagem, é possível contextualizar o estudo de funções e equações trigonométricas, visto que essa disciplina utiliza esses conteúdos no ensino de um método chamado Radiação, no qual se calcula a evapotranspiração ${ }^{5}$ de uma plantação, para saber a temporalidade com que se deve irrigar o plantio.

\footnotetext{
${ }_{5}^{4}$ Instituto Brasileiro de Geografia e Estatística.

5 "a transferência de água para a atmosfera sob a forma de vapor que se verifica em um solo úmido" (Melo e Silva, 2008, p. 27).
} 


\section{Considerações finais}

A efetivação da proposta desse estudo agrega ao ensino de Matemática, em cursos integrados de Institutos Federais de Educação e a outros cursos técnicos ofertados no país, características técnico-profissionais, sem deixar de considerar a importância de aprender a Matemática por ela mesma e trazendo para a sala de aula situações que os alunos e professores reconhecerão como necessárias para o desenvolvimento profissional dos estudantes.

Neste trabalho, a lista de conteúdos e os momentos em que estes podem ser associados às disciplinas técnicas se resumiram ao Curso de Agropecuária, mas os resultados e metodologia utilizada mostram que, na prática, um curso realmente integrado pode ser implantado nos diversos ambiente educacionais do país que ofertam essa modalidade educacional.

A análise dos dados da pesquisa permitiu determinar nas disciplinas técnicas os conteúdos que envolviam a Matemática e momentos em que a interdisciplinaridade e a contextualização podem ser desenvolvidas. Entretanto não se pode deixar de considerar que a efetivação de um currículo integrado depende da vontade de todos os professores envolvidos, inclusive os de Matemática, pois a integração exige o conhecimento de assuntos pertinentes aos cursos integrados que são específicos e laborais. É uma proposta que requer dos docentes e estudantes o distanciamento, mesmo que temporário, de suas zonas de conforto, para que se disponham a realizar articulações entre conteúdos que, aparentemente, não se relacionam, mas que juntos proporcionam a realização de métodos de ensino interdisciplinares e contextualizados que são necessários nessa modalidade de ensino.

\section{Referências}

BOGDAN, R.; BIKLEN, S. Investigação Qualitativa em Educação: fundamentos, métodos e técnicas. 8. ed. Portugal: Porto Editora, 1994. 336 p.

BRASIL. Conselho Nacional de Educação. Parecer CNE n$^{\circ} 15$ de $1^{\circ}$ de junho de 1998. Diretrizes curriculares nacionais para o ensino médio. Brasília, 1998.

BRASIL. Ministério da Educação. Secretaria da Educação Média e Tecnológica. Parâmetros Curriculares Nacionais + . Brasília: MEC, 2002.

BRASIL. Conselho Nacional de Educação e Conselho de Educação Básica. Parecer CNE/CEB no 39 de 8 de dezembro de 2004. Aplicação do Decreto n ${ }^{\circ}$.154/2004 na Educação Profissional Técnica de nível médio e no Ensino Médio. Brasília, 2004. 
BRASIL. Ministério da Educação e Secretaria de Educação Profissional e Tecnológica. Educação Profissional Técnica de Nível Médio Integrada ao Ensino Médio: documento base. Brasília: MEC, 2007.

BRASIL. Congresso Nacional. Lei n⿳ 11.892, de 29 de dezembro de 2008. Institui a Rede Federal de Educação Profissional, Científica e Tecnológica, cria os Institutos Federais de Educação, Ciência e Tecnologia, e dá outras providências. Brasília, 2008.

BRASIL. Conselho Nacional de Educação. Diretrizes Curriculares Nacionais para a Educação Profissional Técnica de Nível Médio em Debate. Brasília, 2010. Disponível em: <http://portal.me c.gov.br/index.php?option=com docman \&view $=$ download \&alias $=6695$-den-paraeducacao-profissionaldebate\&category slug=setembro-2010-pdf\&Itemid=30192>. Acesso em: 07 mar. 2017.

CIAVATTA, M. A formação integrada: a escola e o trabalho como lugares de memória e de identidade. In: FRIGOTTO, G.; RAMOS, M.; CIAVATTA, M. (Org.). Ensino Médio Integrado: concepção e contradições. São Paulo: Ed. Cortez, 2005. p. 83-105.

COLL, César. Psicologia e Currículo: uma aproximação psicopedagógica à elaboração do currículo escolar. 2. ed. São Paulo: Ática, 2006. 200 p.

D’AMBROSIO, U. Educação Matemática: da teoria a prática. 16. ed. Campinas: Papirus, 2001. 121p.

FACHINELO, J. C., NACHTIGAL, J. C. e KERSTEN, E. Fruticultura: fundamentos e práticas. 1. ed. Pelotas: Embrapa, 2008. 182 p.

FAZENDA, I. C. A. Interdisciplinaridade-transdisciplinaridade: visões culturais e epistemológicas. In: (Org.). O Que É Interdisciplinaridade? São Paulo: Ed. Cortez, 2008. p. 17-28.

FRIGOTTO, G.; RAMOS, M.; CIAVATTA, M. (Org.). Ensino Médio Integrado: concepção e contradições. 1. ed. São Paulo: Cortez, 2005. 175 p.

GONÇALVES, H. J. L.; PIRES, C. M. C. Educação matemática na educação profissional de nível médio: análise sobre possibilidades de abordagem interdisciplinares. Bolema, Rio Claro, v. 28, n. 48, p. 230-254, abr. 2014.

LOPES , A. C. O. Os Parâmetros Curriculares Nacionais para o Ensino Médio e a submissão ao mundo produtivo: o caso do conceito de contextualização. Revista Educação e Sociedade, Campinas, v. 23, n. 80, 2002, p. 386-400.

MELLO, J. L. P.; Silva, L. D. B. Irrigação. Rio de Janeiro: UFRRJ, 2008. Disponível em:<http://www .ufrrj.br/institutos/it/deng/leonardo/downloads/Irriga\%e7\%e3o Vers\%e3o3.7.pdf>. Acesso em: 15 jan. 2012.

MINAYO, M. C. S. (Org.). Pesquisa Social: teoria, método e criatividade. 6. ed. Petrópolis: Vozes, 1996. $108 \mathrm{p}$.

PIRES, C. M. C. Formulações basilares e reflexões sobre a inserção da matemática no currículo, visando a superação do binômio máquina e produtividade. Educação Matemática Pesquisa, São Paulo, v. 6, n. 2, p. 29-61, 2004. 
RAMOS, M. Possibilidades e desafios na organização do currículo integrado. In: FRIGOTTO, G.; RAMOS, M.; CIAVATTA, M. (Org.). Ensino Médio Integrado: concepção e contradições. São Paulo: Ed. Cortez, 2005. p. 106-127.

SACRISTAN, J. G. O currículo: uma reflexão sobre a prática. Tradução: Ernani F. da F. Rosa. 3 ed. Porto Alegre: ArtMed, 2000. 352p.

SANTOS, F. P. Ensino Médio Integrado Ao Técnico: uma análise da disciplina matemática. 2012. 115 p. Dissertação (Mestrado em Educação Matemática) - Universidade Federal de Ouro Preto, Ouro Preto, 2012.

SAVIANI, N. Saber Escolar, Currículo e Didática: problemas da unidade conteúdo/método no processo pedagógico. 2. ed. Campinas: Autores Associados, 1998. 198 p.

SAVIANI, N. Currículo: um grande desafio para o professor. Revista de Educação, São Paulo, nº 16, p. 35-38, 2003.

VEIGA, L. A. K., ZANETTI, M. A.; FAGGION, P. L. Fundamentos de Topografia: engenharia cartográfica e de agrimensura. Curitiba: Universidade Federal do Paraná, 2012. Disponível em: <http://www.recife.ifpe.edu.br/topografia/ufpr.pdf>. Acesso em: 12 mai. 2012.

VIANA, M. C. V. Perfeccionamiento del Currículo para la Formación de Profesores de Matemática en la UFOP. 2002. 165 p. Tese (Doctorado en Ciencias Pedagógicas) - Instituto Central de Ciencias Pedagógicas, La Habana, Cuba.2002.

Submetido em Maio de 2016. Aprovado em Novembro de 2016. 